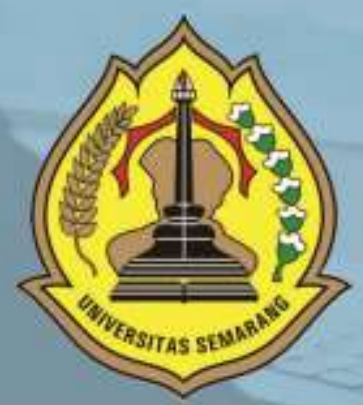

PENGARUH WORK FAMILY CONFLICT, STRES KERJA DAN KEPEMIMPINAN TERHADAP TURNOVER INTENTION KARYAWAN (STUDI PADA SELURUH KARYAWAN BAGIAN PLANNING PRODUCTION AND INVENTORY CONTROL PT. PARKLAND WORLD INDONESIA JEPARA

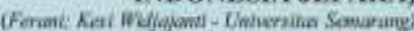

STUDI SOFT SKILL LULUSAN PENDIDIKAN KEJURUAN DI TEMPAT KERJA

Whort-Chiversikio Semorang

ANALISIS IINGKUNGAN INTERNAL DAN EKSTERNAL, PADA UKM PREMIUM PLUS LAUNDRY CABANG MULAWARMAN SEMARANG

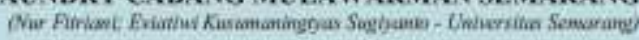

FAKTOR-FAKTOR YANG MEMPENGARUHI PERTIMBANGAN TINGKAT MATERIALITAS AUDIT

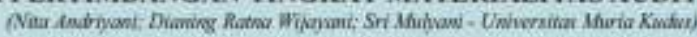

MANAJEMEN LABA DAN FAKTOR-FAKTOR YANG MEMPENGARUHINYA (STUDI EMPIRIS PADA PERUSAHAN MANUFAKTUR DI BEI)

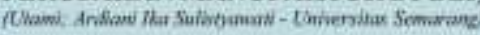

PENDAPATAN ASLI DAERAH, DANA PERIMBANGAN, DAN SISA LEBIH PEMBIAYAAN ANGGARAN TERHADAP PENGALOKASIAN BELANJA MODAL: STUDI PADA KABUPATEN/KOTA DI PROVINSI JAWA TENGAH

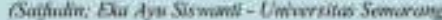

PERSEPSI PENGGUNA JASA TRANS JATENG TERHADAP KUALITAS PELAYANAN ANGKUTAN AGLOMERASI PERKOTAAN TRANS

JATENG

(Studi Kasus Trans Jateng Koridor I Semarang (Tawang) - Bawen)

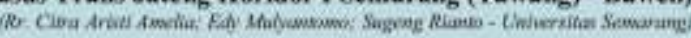

WORTHLESSNESS IS A POWER: MENGAPA ORANG BERSEDIA MENARUH UANG DI APLIKASI GO-PAY

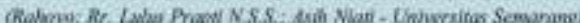

ANALISIS PENGARUH KUALITAS PRODUK, PERSEPSI HARGA, DAN PROMOSI TERHADAP KEPUTUSAN PEMBEIIAN WELLBLUE AL KALINE WATER PITCHER

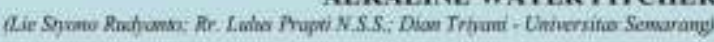

STRATEGI PEMASARAN UNTUK MENINGKATKAN VOLUME PENJUALAN (STUDI KASUS PADA SHOFA CATERING)

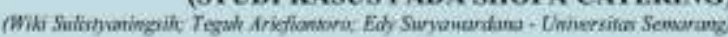

PENGARUH CITRA MEREK, PERSEPSI HARGA, DAN KUALITAS PRODUK TERHADAP KEPUTUSAN PEMBELIAN SEPATU OLAH RAGA MEREK ADIDAS

(Studi di Kota Semarang)

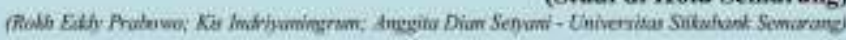

PENGARUH KEMUDAHAN TERHADAP KEPUTUSAN MENGGUNAKAN E-BANKING PADA BNI 46 KC KARANGAYU SEMARANG DENGAN MINAT NASABAH DAN KEPERCAYAAN SEBAGAI VARIABEL. MEDIASI

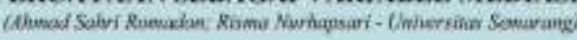

PENELITLAN KEBERLANGSUNGAN USAHA ARDANI INDONESIA SEBAGAI UMKM BERBASIS INDUSTRI KREATIF

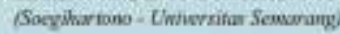

STRATEGI PELAYANAN BUS RAPID TRANSIT (BRT) TRANS SEMARANG

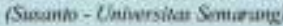

ANALISIS PENGARUH KEPEMIMPINAN, STRES KERJA, DAN LINGKUNGAN KERJA TERHADAP KINERJA KARYAWAN BAGIAN PRODUKSI SEWING PT. SAMWON BUSANA INDONESIA SEMARANG

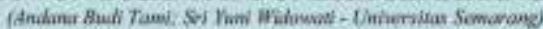




\section{DESKRIPSI}

Majalah IImiah Solusi Mengkaji

Masalah-Masalah Sosial,

Ekonomi dan Bisnis

\section{KETERANGAN TERBIT}

Terbit Pertama Kali Juli 2002

dan SelanjutnyaTerbit Tiga Bulan

Sekali (Januari, April, Juli dan

Oktober)

\section{PENERBIT}

Fakultas Ekonomi USM

\section{ALAMAT PENERBIT}

JL. Soekarno Hatta Semarang

Telp. 024-6702757 Fax. 024-6702272

\section{PENGELOLA}

Editor in Chief : Yohanes Suhardjo, SE, M.Si., Ak, CA Vice Editor Chief : Sugeng Rianto, SE, MM

Managing Editor: Edy Suryawardana, SE, MM

Secretary of Managing Editor : Asih Niati, SE, MM

Administration \& Circulation :

Citra Rizkiana, SE, MM

Layout \& Typesetting : M Burhan Hanif S.Kom, M.Kom

Board of Editors:

1. Prof. Dr. Ir. Kesi Widjajanti, SE, MM (USM)

2. Prof. Drs. Mohammad Nasir, Msi, Ph.D, AK. (USM)

3. Prof. Supramono SE, MBA, DBA (UKSW)

4. Prof. Drs. H. Imam Ghozali, M.Com, Akt, PhD (UNDIP)

5. Prof. Dr. Agus Suroso, MS (UNSOED)

6. Prof. Dr. Widodo, SE, M.Si (UNISSULA)

7. Prof. Dr. Dra. Sulastri, ME, M.Kom (UNSRI)

8. Dr. Ardiani Ika S, SE, MM, Ak, CA, CPA (USM)

\section{KATA PENGANTAR}

Sungguh merupakan kebahagiaan tersendiri bagi kami, takala kami dapat hadir rutin setiap tiga bulan sekali untuk saling bertukar pikiran mengenai hal-hal baru dibidang sosial, ekonomi dan bisnis.

Pada kesempatan ini penerbit menyampaikan terima kasih kepada semua pihak yang telah mengirimkan artikel-artikelnya. Penerbit akan membuka kesempatan seluas-luasnya bagi seluruh kalangan akademisi maupun praktisi baik dari dalam maupun luar Universitas Semarang untuk mempublikasikan karya ilmiahnya.

Penerbitan majalah ilmiah "SOLUSI" kali ini menghadirkan 15 (Lima Belas) artikel yang kami anggap layak untuk diterbitkan, dengan harapan dapat menjadi tambahan referensi bagi para pembaca dan menjadi sumbangan pengembangan persemaian khasanah pengetahuan dibidang sosial, ekonomi dan bisnis.

Akhir kata semoga majalah ilmiah "SOLUSI" dapat memberi manfaat yang sebesar-besarnya.

Hormat Kami 


\section{DAFTAR ISI}

PENGARUH WORK FAMILY CONFLICT, STRES KERJA DAN KEPEMIMPINAN TERHADAP TURNOVER INTENTION KARYAWAN (STUDI PADA SELURUH KARYAWAN BAGIAN PLANNING PRODUCTION AND INVENTORY CONTROL PT. PARKLAND WORLD INDONESIA JEPARA)

(Ferani; Kesi Widjajanti - Universitas Semarang)

STUDI SOFT SKILL LULUSAN PENDIDIKAN KEJURUAN DI TEMPAT KERJA

(Albert - Universitas Semarang)...

ANALISIS LINGKUNGAN INTERNAL DAN EKSTERNAL PADA UKM PREMIUM PLUS

LAUNDRY CABANG MULAWARMAN SEMARANG

(Nur Fitriani; Eviatiwi Kusumaningtyas Sugiyanto - Universitas Semarang)

FAKTOR-FAKTOR YANG MEMPENGARUHI PERTIMBANGAN TINGKAT

MATERIALITAS AUDIT

(Nita Andriyani; Dianing Ratna Wijayani; Sri Mulyani - Universitas Muria Kudus).

MANAJEMEN LABA DAN FAKTOR-FAKTOR YANG MEMPENGARUHINYA

(STUDI EMPIRIS PADA PERUSAHAN MANUFAKTUR DI BEI)

(Utami; Ardiani Ika Sulistyawati - Universitas Semarang)

PENDAPATAN ASLI DAERAH, DANA PERIMBANGAN, DAN SISA LEBIH PEMBIAYAAN ANGGARAN TERHADAP PENGALOKASIAN BELANJA MODAL: STUDI PADA

KABUPATEN/KOTA DI PROVINSI JAWA TENGAH

(Saifudin; Eka Ayu Siswanti - Universitas Semarang).

PERSEPSI PENGGUNA JASA TRANS JATENG TERHADAP KUALITAS PELAYANAN ANGKUTAN AGLOMERASI PERKOTAAN TRANS JATENG

(Studi Kasus Trans Jateng Koridor I Semarang (Tawang) - Bawen)

(Rr. Citra Aristi Amelia; Edy Mulyantomo; Sugeng Rianto - Universitas Semarang)

WORTHLESSNESS IS A POWER: MENGAPA ORANG BERSEDIA MENARUH UANG DI APLIKASI GO-PAY

(Rahoyo; Rr. Lulus Prapti N.S.S.; Asih Niati - Universitas Semarang).

ANALISIS PENGARUH KUALITAS PRODUK, PERSEPSI HARGA, DAN PROMOSI TERHADAP KEPUTUSAN PEMBELIAN WELLBLUE ALKALINE WATER PITCHER

STRATEGI PEMASARAN UNTUK MENINGKATKAN VOLUME PENJUALAN (STUDI KASUS PADA SHOFA CATERING)

(Wiki Sulistyaningsih; Teguh Ariefiantoro; Edy Suryawardana - Universitas Semarang)

PENGARUH CITRA MEREK, PERSEPSI HARGA, DAN KUALITAS PRODUK TERHADAP KEPUTUSAN PEMBELIAN SEPATU OLAH RAGA MEREK ADIDAS

(Studi di Kota Semarang)

(Rokh Eddy Prabowo; Kis Indriyaningrum; Anggita Dian Setyani - Universitas Stikubank Semarang) .121

PENGARUH KEMUDAHAN TERHADAP KEPUTUSAN MENGGUNAKAN E-BANKING PADA BNI 46 KC KARANGAYU SEMARANG DENGAN MINAT NASABAH DAN KEPERCAYAAN SEBAGAI VARIABEL MEDIASI

(Ahmad Sahri Romadon; Risma Nurhapsari - Universitas Semarang) 
PENELITIAN KEBERLANGSUNGAN USAHA ARDANI INDONESIA SEBAGAI UMKM BERBASIS INDUSTRI KREATIF

(Soegihartono - Universitas Semarang)

STRATEGI PELAYANAN BUS RAPID TRANSIT (BRT) TRANS SEMARANG

(Susanto - Universitas Semarang).....

ANALISIS PENGARUH KEPEMIMPINAN, STRES KERJA, DAN LINGKUNGAN KERJA TERHADAP KINERJA KARYAWAN BAGIAN PRODUKSI SEWING PT. SAMWON BUSANA INDONESIA SEMARANG

(Andana Budi Tami; Sri Yuni Widowati - Universitas Semarang). 


\title{
PERSEPSI PENGGUNA JASA TRANS JATENG TERHADAP KUALITAS PELAYANAN ANGKUTAN AGLOMERASI PERKOTAAN TRANS JATENG (Studi Kasus Trans Jateng Koridor I Semarang (Tawang) - Bawen)
}

\author{
Rr. Citra Aristi Amelia \\ Edy Mulyantomo \\ Sugeng Rianto
}

Fakultas Ekonomi Universitas Semarang

Diterima: Agustus 2020, Disetujui: September 2020, Dipublikasikan: Oktober 2020

\begin{abstract}
This research was conducted on the Trans Jateng urban agglomeration transport in Kedungsapur Area Corridor I Semarang (Tawang) - Bawen. The purpose of this study is to describe the perceptions and responses of service users to the service quality of Trans Java Central Corridor I Semarang (Tawang) - Bawen, which has been operating for almost three years.This study uses qualitative methods, using source triangulation, namely observation, interviews, and documentation. Research on the informants is based on purposive sampling (non-probability sample) by establishing the specified criteria and the informants selected based on their knowledge related to the topic of this study. The data analysis method used in the study of perceptions of Trans Jateng service users towards the Trans Jateng Urban Agglomeration Transport Service is an interactive analysis with 4 components consisting of data collection, data reduction, data presentation, and drawing conclusions. The results of this study indicate that the user's perception of the service of Central Java is good and in accordance with the user's expectation. The user hopes that the Central Java Trans services that are rated so far has always be maintained. However, the user said that there were some crews who did not provide excellent service to the users so that they did not meet management's expectations of doing a good job to serve users of Trans Central Java services. This proves the existence of message ambiguity, which is one of the factors in the occurrence of a gap between service quality specifications and service delivery/delivery to users (gap 3), especially in the dimensions of physical evidence and guarantees.
\end{abstract}

Keywords : perception, service quality, gaps, service quality dimensions.

\begin{abstract}
ABSTRAK
Penelitian ini dilakukan pada angkutan aglomerasi perkotaan Trans Jateng Kawasan Kedungsapur Koridor I Semarang (Tawang) - Bawen. Tujuan penelitian ini adalah mendeskripsikan persepsi dan tanggapan pengguna jasa terhadap kualitas
\end{abstract}


pelayanan Trans Jateng Koridor I Semarang (Tawang) - Bawen yang telah beroperasional selama hampir tiga tahun ini.Penelitian ini menggunakan metode kualitatif, dengan menggunakan triangulasi sumber, yaitu observasi, wawancara, dan dokumentasi. Penelitian informan didasarkan pada purposive sampling (non probability sampel) dengan cara menetapkan kriteria yang ditentukan serta informan yang di pilih berdasarkan pengetahuan yang dimiliki terkait topik penelitian ini. Metode analisis data yang digunakan pada penelitian persepsi pengguna jasa Trans Jateng terhadap Pelayanan Angkutan Aglomerasi Perkotaan Trans Jateng ini adalah analisis interaktif yang memiliki 4 komponen yang terdiri dari pengumpulan data, reduksi data, penyajian data, dan penarikan kesimpulan.Hasil penelitian ini menunjukan bahwa persepsi pengguna terhadap pelayanan Trans Jateng sudah baik dan sesuai dengan ekspektasi yang diharapkan oleh pengguna. Pengguna berharap agar layanan Trans Jateng yang di nilai sejauh ini sudah cukup baik agar selalu dipertahankan. Namun pengguna menyampaikan bahwa terdapat beberapa kru yang kurang memberikan pelayanan secara prima kepada pengguna sehingga belum memenuhi harapan manajemen dalam melakukan tugas dengan baik untuk melayani pengguna jasa Trans Jateng. Hal tersebut membuktikan adanya ambiguitas pesan, yang merupakan salah satu faktor terjadinya suatu kesenjangan antara spesifikasi kualitas pelayanan dan pemberian/penyampaian pelayanan kepada pengguna (gap 3), khususnya pada dimensi bukti fisik dan jaminan.

Kata kunci : persepsi, kualitas pelayanan jasa, kesenjangan, dimensi kualitas jasa.

\section{PENDAHULUAN}

Saat ini kebutuhan pergerakan masyarakat untuk memenuhi aktivitasnya sangatlah besar. Adanya transportasi umum akan memudahkan mobilitas masyarakat pengguna angkutan umum untuk mengakses kawasan bangkitan dan tarikan perjalanan di pusat kota, seperti halnya Kabupaten Semarang dan Kota Semarang. Masyarakat berhak mendapatkan pelayanan transportasi yang baik, aman, cepat, dan terjangkau oleh daya beli masyarakatnya. Pemerintah Provinsi Jawa Tengah telah berusaha melakukan reformasi angkutan umum dengan menghimbau dan mewajibkan para pengusaha transportasi untuk mematuhi Standar Pelayanan Minimum (SPM) yang telah ditentukan. Namun para pengusaha angkutan umum eksisting khususnya pengusaha AKDP (Antar Kota Dalam Provinsi) belum dapat memenuhi persyaratan pemerintah untukmemperbaiki layanannya sesuai dengan SPM yang ada. Hal ini dapat di lihat dari kondisi angkutan umum eksisting khususnya AKDP (Antar Kota Dalam Provinsi)dinilai masih belum layak. Kinerjanya dinilai kurang efisien, seperti budaya "ngetem", ugalugalan, terjadinya kekosongan layanan dan kurang terjaminnnya kenyamanan serta keselamatan penumpang.

Dampak yang timbul dari kurang optimalnya kualitas dan pelayanan angkutan umum yakni menurunnya minat masyarakat dalam menggunakan angkutan umum dan meningkatnya jumlah penggunaan kendaraan pribadi. Peningkatan dalam penggunaan angkutan pribadi justru menimbulkan dampak negatif untuk masyarakat. Masalah yang 
timbul antara lain meningkatnya angkakecelakaan pada pengguna kendaraan pribadi, timbulnya kemacetan sehingga dapat menghambat waktu dalam perjalanan, dan juga menambah beban biaya transportasi. Oleh karena itu untuk mengurangi dampak kecelakaan dan kemacetan serta memberikan pelayanan transportasi kepada masyarakat, Pemerintah Provinsi Jawa Tengah berupaya mengembangkan Angkutan Aglomerasi Perkotaan Wilayah Kedungsapur Koridor I Semarang (Tawang) - Bawen.

Saat ini Angkutan Aglomerasi Trans Jateng Koridor I Semarang - Bawen telah beroperasi selama 2 tahun 5 bulan. Pada bulan Juli 2017 Trans Jateng Koridor I di lauching secara langsung oleh Bapak Gubernur Jawa Tengah dengan jumlah armada sebanyak 18 unit bus. Euforia dan antusiasme masyarakat sangatlah tinggi, terlebih lagi dengan pelayanan sesuai dengan SPM dan SOP yang berlaku. Hal ini didukung dengan data jumlah penumpang Trans Jateng Koridor I Semarang - Bawen periode tiga tahun terakhir sebagaimana berikut ini :

\section{Tabel I}

Jumlah Penumpang Trans Jateng Koridor I Semarang (Tawang) - Bawen

\begin{tabular}{|l|c|c|c|}
\hline \multicolumn{1}{|c|}{ BULAN } & 2017 & 2018 & \multicolumn{2}{c|}{2019} \\
\hline Januari & - & 136.444 & 178.628 \\
\hline Februari & - & 127.775 & 166.882 \\
\hline Maret & - & 141.309 & 188.728 \\
\hline April & - & 138.558 & 176.428 \\
\hline Mei & - & 156.321 & 172.712 \\
\hline Juni & - & 136.031 & 160.227 \\
\hline Juli & 74.790 & 165.165 & 181.907 \\
\hline Agustus & 117.16 & 169.779 & 177.772 \\
\hline September & 121.77 & 165.605 & 174.721 \\
\hline Oktober & 137.55 & 175.500 & 181.059 \\
\hline November & 133.05 & 178.228 & 177.621 \\
\hline Desember & 139.98 & 178.774 & 180.709 \\
\hline \hline TOTAL & $\mathbf{7 2 4 . 3 2}$ & $\mathbf{1 . 8 6 9 . 4 8}$ & $\mathbf{2 . 1 1 7 . 3 9}$ \\
\hline
\end{tabular}

Sumber : Balai Transportasi Jawa Tengah, 2020

Konsep Trans Jateng dalam memberikan pelayanan yang aman, nyaman, terjangkau, dan murah menjadikan Trans Jateng lebih unggul dibandingkan dengan angkutan umum eksisting AKDP lainnya. Pelayanan Trans Jateng yang berusaha memenuhi Standar Pelayanan Minimal yaitu keamanan, keselamatan, kenyamanan, keterjangkauan, kesetaraan, dan keteraturan merupakan bentuk dari peningkatan pelayanan angkutan umum yang lebih baik dan berpihak kepada kebutuhan masyarakat masa kini. 


\section{TINJAUAN PUSTAKA}

\section{Loyalitas Pelanggan}

Sikap loyalitas dalam konsumenmerupakan perilaku seseorang yang setia terhadap suatu produk maupun jasa. Sikap loyal ini dapat timbul dari rasa puas terhadap suatu produk, baik barang maupun jasa yang telah dirasakan oleh konsumen. Menutut Tjiptono loyalitas pelanggan merupakan komitmen pelanggan terhadap suatu merek, toko, atau pemasok, berdasarkan sikap yang sangat positif dan tercermin dalam pembelian ulang yang konsisten (2009:387).

\section{Kepuasan Pelanggan}

Pada umumnya perusahaan bertujuan untuk memenuhi kebutuhankonsumen dan juga memuaskan konsumennya dengan nilai-nilai tertentu. Sangadji dan Sopiah mengemukakan bahwa kepuasan konsumen dapat menciptakan dasar yang baik bagi pembelian ulang serta terciptanya loyalitas konsumen; membentuk rekomendasi dari mulut ke mulut yang dapat menguntungkan perusahaan (2013:182). Menurut Kotler, kepuasan adalah perasaan senang atau kecewa seseorang yang timbul karena membandingkankinerja yangdipresepsikan produk (atau hasil) terhadap ekspektasi mereka (2009:138).

\section{Kualitas}

Salah satu aspek yang perlu diperhatikan dalam menawarkan barang maupun jasa kepada pasar adalah kualitas dari produk atau jasa tersebut. Kualitas seringnya menjadi pertimbangan utama seseorang dalam menentukan produk atau jasa yang akan dipilih. Kotler dan Keller (2009:143) dalam bukunya menyatakan bahwa kualitas adalah totalitas fitur dan karakteristik produk atau jasa yang bergantung pada kemampuannya untuk memuaskan kebutuhan yang dinyatakan atau tersirat. Kualitas menjadi faktor penting yang berpengaruh dalam penciptaan dan penentu kepuasan pengguna setelah melakukan pembelian dan pemakaian terhadap suatu produk atau jasa tersebut.

\section{Kualitas Pelayanan}

Tjiptono dan Chandra (2012:74) kualitas pelayanan mencerminkan perbandingan antara tingkat layanan yang disampaikan perusahaan dibandingkan ekspektasi pelanggan. Kualitas layanan diwujudkan melalui pemenuhan kebutuhan dan keinginan pelanggan serta ketepatan penyampaian dalam mengimbangi atau melampaui harapan pelanggan. Parasuraman, et al. (1985)dalam TjiptonodanChandra(2012:78) mengidentifikasikan ada 10 indikator kualitas pelayanan, yang dirangkum menjadi 5 indikator yaitu, Reliabilitas (realiability), Daya Tanggap (responsiveness), Jaminan (assurance), Empati (empathy), dan Bukti Fisik (tangibles).

\section{Model Kualitas Jasa}

Model kualitas jasa menyoroti kebutuhan utama untuk menghantarkan kualitas jasa yang tinggi guna memenuhi kepuasan pelanggan. Parasuraman (2002,dalam Dr. 
Etta, 2013:101)mengidentifikasikan lima gapkesenjangan) yang menyebabkan kegagalan penyampaian jasa. Penjelasan lima gap tersebut adalah sebagai berikut :

1. Gap antara harapan konsumen dan persepsi manajemen, yaitu adanya perbedaan antara penilaian pelayanan menurut pengguna jasa dan persepsi manajemen mengenai harapan pengguna jasa. Kesenjangan ini terjadi karena kurangnya orientasi penilaian pemasaran, pemanfaatan yang tidak memadai atas temuan penelitian, kurangnya interaksi antara pihak manajemen dan pelanggan, komunikasi dari bawah ke atas yang kurang memadai,serta terlalu banyak tingkatan manajemen.Gap antara persepsi manajemen terhadap harapan konsumen dan spesifikasi kualitas jasa. Kesenjangan terjadi antara lain karena tidak memadainya

2. komitmen manajemen terhadap kualitas jasa, persepsi mengenai ketidaklayakan, tidak memadainya standarisasi tugas, dan tidak adanya penyusunan tujuan.

3. Gap antara spesifikasi kualitas jasa dan penyampaian jasa (service delivery). Kesenjangan ini terutama disebabkan oleh faktor-faktor berikut:

a. Ambiguitas pesan, yaitu sejauh mana pegawai dapat melakukan tugas sesuai dengan harapan manajer dan tetap bisa memuaskan pelanggan;

b. Konflik pesan, yaitu sejauh mana pegawai meyakini bahwa mereka tidak memuaskan semua pihak;

c. Kesesuaian pegawai dengan tugas yang harus dikerjakan;

d. Kesesuaian teknologi yang digunakan pegawai;

e. Sistem pengendalian dari atasan, yaitu tidak memadai sistem penilaian dan sistem imbalan;

f. Kontrol yang dirasakan (perceived control), yaitu sejauh mana pegawai merasakan kebebasan atau fleksibilitas untuk menentukan cara pelayanan;

g. Kerja tim, yaitu sejauh mana pegawai dan manajemen merumuskan tujuan untuk memuaskan pelanggan secara bersama-sama dan terpadu.

4. Gap antara penyampaian jasa dan komunikasi eksternal. Ekspektasi pelanggan atas kualitas pelayanan dipengaruhi oleh pernyataan yang dibuat oleh perusahaan mengenai komunikasi pemasaran. Kesenjangan ini terjadi karena :

a. Tidak memadainya komunikasi horizontal dan;

b. Adanya kecenderungan untuk memberikan janji yang berlebih.

5. Gap antara jasa yang dirasakan dan jasa yang diharapkan, yaitu adanya perbedaan persepsi antara jasa yang dirasakan dan yang diharapkan oleh pelanggannya. Jika keduanya terbukti sama, perusahaan akan memperoleh citra dan dampak positif. Namun, bila yang diterima lebih rendah dari yang diharapkan, kesenjangan ini akan menimbulkan permasalahan bagi perusahaan

\section{Angkutan Aglomerasi}

Pengertian angkutan tercantum pada Peraturan Pemerintah Republik Indonesia Nomor 74 Tahun 2014 Tentang Angkutan Jalan. Angkutan merupakan perpindahan orang dan/arau barang dari satu tempat ke tempat lain dengan menggunakan kendaraan di ruang lalu lintas jalan. Pada Peraturan Pemerintah Republik Indonesia Nomor 37 
Tahun 2011 Tentang Forum Lalu Lintas dan Angkutan Jalan disebutkan dalam pasal 1 bahwa Kawasan aglomerasi perkotaan adalah kawasan perkotaan yang terdiri atas sebuah kawasan perkotaan yang berdiri sendiri atau kawasan perkotaan inti dengan kawasan perkotaan di sekitarnya yang saling memiliki keterkaitan fungsional yang dihubungkan dengan sistem jaringan prasarana wilayah yang terintegrasi dan membentuk sebuah sistem. Angkutan aglomerasi dapat dikatakan sebagai angkutan AKDP (Antar Kota Dalam Provinsi). AKDP adalah Angkutan dari satu kota ke kota lain yang melalui antar daerah kabupaten/kota dalam 1 (satu) daerah provinsi dengan menggunakan Mobil Bus umum yang terikat dalam Trayek (PM No. 15 tahun 2019 tentang penyelenggaraan angkutan orang dengan kendaraan umum dalam trayek). Sehingga angkutan aglomerasi merupakan angkutan pada kawasan perkotaan yang melewati dua kabupaten/kota dengan adanya suatu interaksi kegiatan antar kawasan dan menimbulkan mobilitas penduduk.

\section{Standar Pelayanan Angkutan Massal}

Kebijakan standar pelayanan angkutan massal perkotaan telah diatur secara khusus oleh peraturan Menteri Perhubungan Republik Indonesia.Kebijakan tersebut diatur dalam Peraturan Menteri Nomor 10 Tahun 2012 Tentang Standar Pelayanan Minimal Angkutan Massal Berbasis Jalan yang kemudian dirubah menjadi Peraturan Menteri Nomor 27 Tahun 2015 Perubahan Atas Peraturan Menteri Perhubungan Nomor 10 Tahun 2012 Tentang Standar Pelayanan Minimal Angkutan Massal Berbasis Jalan. Didalam peraturan tersebut memuat definisi dari Standar Pelayanan Minimal, yangmerupakan suatu persyaratanpenyelenggaraan angkutan massal berbasis jalan mengenai jenis dan mutu pelayanan yang berhak diperoleh setiap pengguna jasa angkutan masal berbasis jalan secara minimal. Sedangkan pada Pasal 3 ayat 3 menyebutkan bahwa jenis pelayanan yang dimaksud meliputi keamanan,keselamatan, kenyamanan, keterjangkauan, kesetaraan, dan keteraturan.

a. Keamanan : terbebasnya Pengguna Jasa dari gangguan perbuatan melawan hukum dan atau rasa takut.

b. Keselamatan : terhindarnya dari risiko kecelakaan disebabkan oleh faktor manusia, sarana dan prasarana.

c. Kenyamanan : memberikan suatu kondisi nyaman, bersih, indah dan sejuk yang dapat dinikmati Pengguna Jasa.

d. Keterjangkauan: memberikankemudahan bagi Pengguna Jasa mendapatkan akses Angkutan Massal Berbasis Jalan dan tarif yang terjangkau.

e. Kesetaraan : memberikan perlakuan khusus berupa aksesibilitas, prioritas pelayanan, dan fasilitas pelayanan bagi Pengguna Jasa penyandang cacat, manusia usia lanjut, anak-anak, dan wanita hamil.

f. Keteraturan : memberikan kepastian waktu pemberangkatan dankedatangan mobil bus serta tersedianya fasilitas informasi perjalanan bagi Pengguna Jasa. 
Standar pelayanan tersebut diatas yang harus dipenuhi oleh penyelenggara angkutan massal, baik badan usaha milik negara, badan usaha milik negara, dan badan hukum lainnya (perusahaan angkutan umum).

\section{METODE PENELITIAN}

Penelitian ini menggunakan metode kualitatif interaktif,yaitu studi yang mendalam menggunakan teknik pengumpulan data langsung dari informan yaitu pengguna jasa Angkutan Aglomerasi Trans Jateng Koridor I Semarang (St. Tawang) Bawen. Sedangkan Teknik pengumpulan data yang digunakan dalam penelitian ini adalah wawancara, observasi, dan dokumentasi.

Sumber data yang digunakan pada penelitian ini adalah data primer yang diperoleh langsung di lapangan melalui jawaban informan melalui wawancara singkat. Informan yang akan diwawancarai dalam penelitian ini adalah pengguna jasatransportasi Trans Jateng pada Koridor I Semarang (St.Tawang) - Bawensebanyak 6 informan dengan kriteria 3 penumpang umum, 2 pelajar, 1 buruh. Selain ituKoordinator Layanan Trans Jateng pada Koridor I Semarang (St.Tawang) - Bawen dan Kepala Balai Transportasi Jawa Tengah juga akan menjadi informan guna pengecekan atau pembanding hasil data penelitian agar lebih akurat dan valid. Profil informan kunci pada penelitian adalah sebagai berikut :

\begin{tabular}{|l|l|r|l|l|}
\hline Nama & Pekerjaan & \multicolumn{1}{l|}{$\begin{array}{l}\text { Umur } \\
\text { (th) }\end{array}$} & Kriteria & $\begin{array}{l}\text { Kode } \\
\text { Informan }\end{array}$ \\
\hline Trisia & Pegawai Swasta & 48 & Penumpang Umum & 1 \\
\hline Ika & Buruh & 27 & Penumpang Buruh & 2 \\
\hline Ines & Pelaljar & 17 & Penumpang Pelajar & 3 \\
\hline Nadia & Pelaljar & 44 & Penumpang Pelajar & 4 \\
\hline Indi & Ibu rumah tangga & 45 & Penumpang Umum & 5 \\
\hline Margi & Ibu rumah tangga Umum & 6 \\
\hline Cito Eko & $\begin{array}{l}\text { Pegawai Non Pns } \\
\text { (Koorlay Trans Jateng) }\end{array}$ & 28 & - & 7 \\
\hline $\begin{array}{l}\text { Joko } \\
\text { Setyawan }\end{array}$ & PNS (Kabalai Trans) & & - & 8 \\
\hline
\end{tabular}

Metode analisis data yang digunakan pada penelitian persepsi pengguna jasa Trans Jateng terhadap Pelayanan Angkutan Aglomerasi Perkotaan Trans Jateng ini adalah analisis interaktif. Model ini ada 4 komponen analisis yaitu: pengumpulan data, reduksi data, penyajian data, dan penarikan kesimpulan.

\section{HASIL DAN PEMBAHASAN}

\section{Potret Balai Transportasi Jawa Tengah}

Balai Transportasi Jawa Tengah (Balai Trans Jateng) memiliki kewajibanuntuk melaksanakan tugas teknis operasional dan/ atau kegiatan teknis penunjang tertentu di dinas, bidang sarana dan prasarana dan operasional transportasi Jawa Tengah. Saat ini 
Balai Trans Jateng telah memiliki 3 (tiga) koridor angkutanaglomerasi perkotaan yaitu Wilayah Kedungsapur koridor I Semarang (Tawang) - Bawen dan koridor II Semarang - Kendal serta Wilayah Barlingmascakeb koridorPurwokerto - Purbalingga.

\section{Potret Pelayanan Jasa Trans Jateng}

Trans Jateng Koridor I Stasiun Tawang - Terminal Bawen diresmikanlangsung oleh Bapak Ganjar Pranowo selaku Gubernur Jawa Tengah pada tanggal7 Juli 2017 di Terminal Bawen Kabupaten Semarang. Trans Jateng Koridor ISemarang (Tawang) Bawen memiliki panjang rute $36,5 \mathrm{~km}$ yang dilayani dengan 25 armada bus untuk melayani penumpang dari arah Kabupaten Semarangke Semarang dan sebaliknya. Jam operasional pelayanan Trans Jateng koridor I Semarang (Tawang) - Bawen yaitu dari pukul 05.00 sampai dengan pukul 21.00.Keberangkatan dimulai jam 05.00 dari Stasiun Tawang dan Terminal Bawen.

Trans Jateng melayani penumpang setiap harinya dengan tarif yang berbeda, sebelumnya dalam Peraturan Gubernur Jawa Tengah Nomor 29 Tahun 2017 tentang Tarif Angkutan Aglomerasi Perkotaan Bus Rapid Transit Jateng Kawasan Kedungsapur Koridor I (Stasiun Tawang-Bawen) tarif Trans Jateng ditetapkan untuk penumpang umum sebesar Rp. 3.500,- dan untuk pelajar dan buruh sebesar Rp. 1.000,-. Namun pada 1 April 2019 telah diberlakukan perubahan tarif sesuai dengan Peraturan Gubernur Jawa Tengah nomor 4 tahun 2019 tentang Tarif Angkutan Aglomerasi Perkotaan Bus Rapid Transit Trans Jateng. Ketentuan tarif sesuai Pergub untuk umum sebesar Rp. 4.000,-dan untuk pelajar, buruh serta veteran sebesar Rp. 2.000,-. Tarif tersebut diberlakukan jauh dekat sama (flat) sehingga dapat dikatakan murah dan terjangkau.

\section{Analisis Data Penelitian}

\section{Hasil Observasi}

Observasi pelayanan Trans Jateng dilakukan dengan meninjau langsung secara on bus pelayanan operasional Trans Jateng pada waktu pagi hari, siang hari, dan sore hingga malam hari. Hal ini dimaksudkan agar peneliti merasakan pelayanan Trans Jateng secara pribadi dan meninjau kondisi bus serta suasana di dalam pelayanan bus Trans Jateng

Observasi pada pagi hari dilakukan pada pukul 08.00 WIB dengan menaiki bus Trans Jateng nomor lambung 4 dari halte Tembalang hingga halte Stasiun Tawang. Kondisi bus Trans Jateng bersih, suhu AC dingin, kondisi running text sebagai media informasi pemberhentian halte berikutnya berjalan dengan baik, suara pemberitahuan informasi pemberhentian halte terdengar jelas. Terdapat berbagai sticker didalam bus terkait aturan yang tidak diperbolehkan penumpangdi dalam bis dan juga himbauan kepada penumpang seperti stiker untuk pemisahan penumpang pria dan wanita.

Pramujasa terlihat berpakaian rapi memakai batik dan sepatu dengan atribut lengkap. Setiap penumpang masuk kedalam bus, pramujasa selalu menyapa dan mengarahkan penumpang pria ke bagian depan bus dan penumpang wanita ke bagian belakang bus. Didalam bis pramujasa terlihat menghanpiri satupersatu penumpang 
untuk menjual tiketnya dengan mesin E-Tiketingnya. Dari pengamatan saya, beberapa membayar dengan tarif umum sebesar Rp. 4.000,- dan ada juga yang membayar dengan tarif pelajar sebesar Rp. 2000,-. Seperti para sekelompok pelajar yang duduk di kursi belakang bis, merea membayar dengan menunjukan kartu pelajarnya kepada pramujasa dan kemudian pramujasa mencetak karcis pada mesin E-tiketingnya. Setelah kebeberapa penumpang akhirnya pramujasa tersebut menghampiri saya untuk menjual tiketnya, karena saya tidak menunjukan kartu Mahasiwi maka saya membayar tiket sebagai penumpang umum sebesar Rp. 4.000,-. Menurut saya harga tersebut masih tergolong ringan dan murah jika dibandingkan bila saya naik ojek online atau angkutan umum lainnya. Terlebih fasilitas yang saya dapatkan jauh lebih baik dengan harga yang cukup murah tersebut. Jumlah penumpang pada bus lambung 4 dari Halte Tembalang hingga halte akhir St. Tawang tidak terlalu banyak, ruang di dalam bis untuk penumpang masih sangat longgar.Selama perjalanan pengemudi mengendarai bus dengan baik, tidak ngebut dan kecepatannya cenderung stabil, hal ini juga didukung dengan kondisi lalu lintas pada pagi hari yang tidak padat. Sehingga dengan kondisi bus yang belum banyak penumpang, AC yang cukup dingin dan perjalanan yang lancar selama dari halte Tembalang hingga ke halte Stasiun Tawang menyebabkan perjalanan saya terasa nyaman

Observasi pada siang hari dilakukan pada pukul 12.00 WIB dengan titik awal keberangkatan saya di halte Terminal Bawen. Sebelum menuju ruang tunggu saya sempatkan melihat ke pool dimana bis Trans Jateng parkir. Terlihat berderet bis Trans Jateng dengan kondisi bis yang masih sangat bagus. Saya tertarik dengan gambar pada bis Trans Jateng yang khas dengan maskot burung kepodang berbeskap dan juga satu gambar wisata di Kabupaten Semarang dan Kota Semarang yang ada di setiap bis.

Setelah melihat-lihat eksterior bis Trans Jateng saya langsung menuju ke ruang tunggu. Kondisi ruang tunggu penumpang di halte Terminal Bawen sudah memadai. Tersedia 24 kursi untuk calon penumpang, tempat sampah, running text yang bertuliskan himbauan agar penumpang berhati-hati dengan barang bawaannya serta sebagai informasi halte keberangkatan awal di Terminal Bawen, dan juga tersedia infografis terkait rute dan halte di sepanjang koridor I Semarang (Tawang) - Bawen. Suasana di ruang tunggu bis Trans Jateng pada halte Terminal Bawen tidak terlalu ramai. Sehinga kemungkinan saya dapat langsung naik ke bis yang akan berangkat. Ketika bis Trans Jateng bergerak dari pool menuju ke ruang tunggu, penumpang langsung besiap-siap menuju ke halte high deck. Satu-persatu penumpang, begitu pula dengan saya, segera masuk ke dalam bis lambung 25 yang sudah siap berada di halte. Ketika saya masuk pramujasa langsung mengarahkan saya kebagian belakang.

\section{Hasil Wawancara}

Wawancara dilakukan untuk mengetahui persepsi pengguna jasa terhadapkualitas pelayanan pada jasa transportasi Trans Jateng di Koridor I Semarang (Tawang) - Bawen. Pelaksanaan wawancara dengan informan kunci dilakukan secara lisan dan online (via aplikasi Skype dan WhatsApp). Berdasarkan hasil wawancara 
yang telah dilakukan dengan perumusan pola dan konsepmaka ditemukan pembahasan dari lima dimensi kualitas jasa dan juga terlihat adanya gap atau kesenjangan yang menyebabkan kegagalan penyampaian jasa. Pembahasan terkait lima dimensi kualitas jasa dan analisis kesenjangan kualitas jasa pada Pelayanan Angkutan Aglomerasi Perkotaan Trans Jateng Koridor I Semarang (Tawang) - Bawen adalah sebagai berikut :

\section{Lima Dimensi Kualitas Jasa}

\section{1) Keandalan}

Trans Jateng koridor I Semarang (Tawang) - Bawen telah melayani masyarakat sejak tahun 2017. Masyarakat sering memanfaatkan pelayanan ini untuk melakukan perjalanan jauh antar Kabupaten Semarang dan Kota Semarang. Bahkan mayarakat juga melakukan perpindahan moda transportasi agar dapat menggunakan Trans Jateng. Pelayanan ini digunakan dengan berbagai macam tujuan pergerakan yaitu bekerja, menuntut ilmu, sarana rekreasi dan kepentingan sosial. Hal ini sesuai dengan maksud dan tujuan penyelenggaraan layanan Angkutan Aglomerasi Perkotaan Trans Jateng Koridor I Semarang (Tawang) - Bawen. Balai Transportasi Jawa Tengah sebagai organisasi pemerintah menjalankan amanat undang-undanguntuk menyediakan angkutan antar kota dalam provinsi. Penyediaan angkutan massal dilakukan dengan melihat potensi pergerakan di Jawa Tengah, dengan merintis layanan pertama di Kawasan Kedungsapur. Kota Semarang dan Kabupaten Semarang merupakan dua wilayah yang mewakili pergerakan terbesar di Ibu Kota Jawa Tengah. Sehingga dibukalah layanan Trans Jateng Koridor I Semarang (Tawang) - Bawen.

Manajemen Trans Jateng berusaha menciptakan gambaran/citra pelayanan yang teratur, nyaman, aman, tarif bersubsidi yang menjadikan layanan ini terjangkau sehingga masyarakat tertarik menggunakan layanantransportasi antar dua kabupaten/kota ini. Dari sisi persepsi pengguna yang telah merasakan layanan Trans Jateng, pengguna merasakan bahwa menggunakan Trans Jateng jauh lebih nyaman, hemat, cepat, murah, mudah dan pelayanannya bagus sehingga menjadi pilihan dalam melakukan pergerakan guna memenuhi tujuan perjalanannya. Bahkan dengan adanya layanan ini juga memicu pergerakan baru sehingga layanan ini dimanfaatkan masyarakat yang belum pernah ke daerah Bawen. Jika melihat kondisi saat ini, layanan angkutan umum konvensional kalah berrsaing dan kurang diminati oleh masyarakat. Hal ini juga dipengaruhi dengan tidak adanya kepastian layanan pada angkutan umum. Tidak ada perhatian pada kenyamanan dan keamanan penumpang, tidak teratur operasionalnya. Sehingga Balai Trans Jateng memfasilitasi kebutuhan mobilitas masyarakat dengan layanan yang representatif. Sesuai dengan standar pelayanan minimum angkutan masal yang mempertimbangkan aspek keamanan, kenyamanan, keteraturan,keterjangkauan, kesetaraan dan keselamatan. Dibukanya layanan Trans Jateng koridor I Semarang (Tawang) - Bawen menyebabkan adanya peralihan moda dari kendaraan pribadi ke Trans Jateng. Selain itu cukup banyak yang berpindah dari angkutan umum ke Trans Jateng. 
Dampak dan manfaat yang dirasakan pengguna setelah merasakan pelayanan Trans Jateng yaitu dapat membantu meringankan biaya transport.Sebelumnya pengguna harus mengeluarkan biaya untuk bensin dan jika naik angkutan umum konvensional harga yang tidak menentu karena ditentukan sendiri oleh pengemudi bergantung dari jarak perjalanannya. Namun dengan Trans Jateng, pengguna akan mendapatkan kepastian harga, waktu, dan kemudahan dalam mendapatkan pelayanan transportasi. Bahkan pengguna akan lebih terjamin dalam mendapatkan kenyamanan dan keamanan saat melakukan perjalanan. Fenomena diatas menggambarkan telah terjadinya peralihan perilaku, dimana sebelumnya pengguna jasa transportasi mengandalkan kendaraan pribadi maupun kendaraan umum konvensional untuk memenuhi kebutuhan pergerakannya, kemudian beralih dengan adanya layanan Trans Jateng. Sesuai dengan delapan kategori faktor-faktor yang menyebabkan perilaku peralihan pelanggan oleh Keaveney (1995, dalam Kotler dan Keller, 2009:48) peralihan perilaku ini disebabkan oleh faktor-faktor sebagai berikut :

1. Penetapan harga : harga yang ditetapkan pada angkutan umum konvensional tidak pasti dan tidak tetap;

2. Ketidaknyamanan : waktu pelayanan yang tidak pasti, lokasi pelayanan dan jam layanan tidak menentu, kebiasaan ngetem;

3. Kegagalan layanan inti : pelayanan transportasi yang tidak teratur dan terjadwal;

4. Kegagalan pemenuhan jasa : tidak memperhatikan kebutuhan dasarpenumpang, pelayanan kurang baik;

5. Respons terhadap kegagalan pelayanan : tidak ada respons dalam menanggapi keluhan pengguna, cenderung negatif;

6. Persaingan : persaingan dalam mendapatkan penumpang menyebabkan seringnya kebut-kebutan;

7. Masalah etika : keamanan tidak terjamin, kesopanan terkadang kurang diperhatikan.

\section{2) Bukti Fisik}

Bukti fisik dapat dilihat dari bagaimana Trans Jateng memvisualisasikan atau mempresentasikan layanan yang diberikan kepada pengguna. Sehingga sangat penting untuk mengelola bukti fisik guna mewujudkan pelayanan jasa yang sifatnya tidak dapat dilihat dan dirasakan sebelum pengguna merasakan layanan tersebut.

Terkait jadwal pelayanan bis Trans Jateng. beberapa pengguna menilai bahwa kepastian waktu kedatangan bis sudah cukup tepat waktu. Walaupun waktu antar bis cukup konsisten antara 5-15 menit dan jika ada hambatan dilapangan waktu kedatangan bis dapat mencapai 25 menit. Disaat ada hambatan dilapangan, kru akan menginfokan kepada penumpang jika kedatangan bis akan mengalami keterlambatan. Namun masih ada pengguna yang kurang puas dengan waktu kedatangan bis di jam-jam ramai terlebih pada jam tersebut bis banyak yang penuh sehingga menyebabkan antrian menunggu bis.

Agar kru Trans Jateng dapat memberikan pelayanan yang baik kepada pengguna jasa manajemen Trans Jateng membekali krunya dengan pelatihan SDM. Hal ini dilakukan karena kunci penting agar kru dapat memberikan pelayanan yang baik adalah 
dengan peningkatan mutu SDM. Pelatihan tersebut meliputi attitude, karakteristik, pengetahuan terkait operasional dan konsep dasar pelayanan publik. Selain itu para kru dituntut terus menjaga kompetensi pelayanan. Pelayanan merupakan hal utama yangselalu ditekankan kepada kru agar selalu ramah dan komunikatif serta memahami teknis kendaraan dan operasional. Hal tersebut akan membantu kru dalam menghadapi dan melayani pengguna. Selain itu manajemen memiliki cara tersendiri dalam mengelola dan menjaga agar Trans Jateng memiliki pelayanan yang prima. Manajemen Trans Jateng selalu berupaya mengatur jadwal kru dan memberikan perhatian kepada kru dengan segala keterbatasan yang dimiliki. Hal ini dimaksudkan agar kru dapat bertugas dengan fresh, memiliki perasaan yang selalu terjaga kesiapannya, kemauan untuk melayani selalu ada setiap saat, merasa senang, dihargai, dan diakui. Dengan demikian kru memiliki kemauan untuk bekerja dengan baik dan menjaga kualitas pelayanannya. Hasil wawancara menunjukan bahwa persepsi pengguna terkait pelayanan kru Trans Jateng, pengguna menilai bahwa pelayanan kru Trans Jateng sudah bagus. Kru dinilai rapi dalam berpakaian, ramah, dan sopan. Dalam pelaksanaan Standar operasional prosedur (SOP), kru dihimbau untuk selalu mengikuti SOP yang ada dan saat ini sudah diterapkan oleh kru. Namun pengguna juga mengatakan bahwa ada beberapa kru yang kurang peduli dan penerapan 3S kurang baik. Pernyataan tersebut juga dibenarkan oleh Koordinator Layanan, bahwa masih ada berberapa oknum yang tidak mematuhi SOP. Upaya tindak lanjut yang dilakukan bagi para kru yang melanggar SOP akan dikenakan sanksi teguran, surat peringatan atau skorsing. Hal ini dapat terjadi jika kru terpengaruh oleh suasana atau kru sedang tidak dalam kondisi terbaiknya, sehingga pelayanan menjadikurang prima dan dapat berpengaruh dalam penghantaran nilai kepada pelanggan.

\section{3) Tanggapan (Responsif)}

Salah satu cara guna memahami apa yang diinginkan pelanggan serta memperhatikan kepuasan pengguna jasa adalah dengan mencatat masukan dan keluhan dari pengguna. Manajemen Trans Jateng menyediakan kanal aduan dari berbagai media komunikasi agar memudahkan pengguna dalam meyampaikan aduannya. Kanal aduan ini berfungsi sebagai sarana pengumpulan informasi dari pengguna terkait saran masukan serta pengguna dapat secara proaktif ikut menilai kinerja kru dan layanan Trans Jateng. Jika ada hal yang ingin disampaikan, pengguna harus menginfokan secara jelas aduannya agar pihak Trans Jateng secara cepat menindaklanjuti masukan dan keluhan tersebut. Upaya ini merupakan suatu bentuk itikad baik dalam memahami dan menangani pengalaman negatif yang dirasakan pengguna secara tepat.

Pengguna menilai bahwa pelayanan saat ini sudah bagus. Berdasarkan pengamatan selama menggunakan Trans Jateng, ada peningkatan dari manajemen Trans Jateng dalam menanggapi masukan dan keluhan pengguna. Manajemen dinilai cepat dalam menanggapi komplain serta mengeksekusi masukan dan keluhan yang ada. Namun perlu ada peningkatan dalam pelayanan dan penambahan informasi pada aplikasi Trans Jateng. Pengguna telah memanfaatkan kanal aduan untuk menyampaikan 
masukan dan keluhan mereka. Namun ada juga pengguna yang tidak tahu bagaimana atau kemana mereka menyampaikan masukandan keluhan tersebut. Kotler dan Keller (2009:143) menyatakan bahwa sesempurna apapun rancangan dan implementasi sebuah program pemasaran, kesalahan akan terjadi. Sehingga hal terbaik yang dapat dilakukan adalah mempermudah pengguna untuk dapat menyampaikan keluhan dan masukan. Seperti yang sudah dilakukan oleh manajemen Trans Jateng dengan menyediakan nomor Whats App, Twitter, Facebook, Instagram dan email untuk mempercepat komunikasi dua arah. Sehingga segala masukan dan keluhan dapat diselesaikan dengan cepat dan dengan mendengarkan pengguna guna meningkatkan kualitas jasa dan kepuasan pengguna jasa.

\section{4) Jaminan}

Layanan Trans Jateng didukung dengan ketersediaan SDM yang bertugas menjaga keamanan penumpang. Guna mendukung kelancaran operasional, terdapat kru operator bernama petugas lintas yang bertanggungjawab menjaga keamanan di bis dan di halte. Selain itu terdapat kru Trans Jateng, yaitu Koorlay PPA dan Timer di lapangan yang bertanggungjawab dalam kepastian dan kelancaran pelayanan. Kru berkerja sebagai tim bertanggung jawab terkait operasional teknis baik itu dari segi keamanan, keselamatan dan operasional. Sehingga sangat penting untuk selalu menjaga kerjasama antar SDM agar jaminan keamanan dan keselamatan penumpang terjaga dengan baik.

Keamanan penumpang selama perjalanan dinilai aman. Selain itu adanya peraturan pemisahan penumpang bagi perempuan dan laki-laki sehingga akan lebih aman bagi penumpang perempuan guna menjaga darihal yang tidak diinginkan selama perjalanan. Jaminan keamanan barang bawaan penumpang dinilai aman. Terlebih dengan kru yang peduli dengan ikut menjaga barang bawaan dan jika ada barang yang tertinggal, kru menyimpan barang tersebut.

Dibukanya layanan Trans Jateng koridor I Semarang (Tawang) - Bawen dinilai efektif dalam mengurangi kemacetan. Hal ini diperkuat dengan adanya fenomena perpindahan moda dari pengguna kendaraan pribadi ke Trans Jateng. Peralihan ini juga dapat menekan angka kecelakaan lalu lintas pada kendaraan bermotor pribadi. Supir Trans Jateng dalam mengemudi sudah menaati aturan lalu lintas dan cepat sehingga tepat waktu. Akan tetapi masih ada beberapa kru pengemudi yang terlalu cepat bahkan ngebut dalam mengemudi kendaraannya sehingga dapat membahayakan keamanan dan keselamatan penumpang. Hal ini dapat memberikan penilaian negatif pada pelayanan Trans Jateng, walaupun manajemen Trans Jateng telah berinvestasi dalam pelatihan pramudi dengan mengajarkan cara mengemudi dan berlalu lintas yang baik. Namun realitanya, beberapa pengemudi belum dapat memenuhi harapan manajemen untuk menjalankan tugasnya dengan baik. Sehingga dapat dinilai pramudi masih kurang baik dalam menghantarkan gambaran pelayanan yang aman kepada penumpang. 


\section{5) Empati}

Dalam melaksanakan tugasnya melayani penumpang, pramujasa dinilai bersikap peduli kepada penumpang, terlebih kepada ibu hamil dan lansia. Pramujasa dinilai ramah, baik dan memberikan perlakuan khusus kepada anak kecil, ibu hamil, lansia dan disabilitas dengan berusaha mencarikan tempat duduk. Pramujasa selalu mengingatkan kepada penumpang yang lebih muda untuk memberikan tempat duduk kepada yang lebih tua. Hal ini membuktikan bahwa pramujasa memberikan pelayanan yang mengutamakan kepentingan terbaik untuk pengguna dengan menghormati dan memberikan perhatian. Selain itu pramujasa selalu memisahkan penumpang perempuan dan laki-laki dengan mengarahkan penumpang laki-laki di bagian depan dan perempuan di bagian belakang bis. Perlakuan khusus kepada penumpang perempuan dan laki-laki ini menunjukan suatu bentuk kepedulian agar menjaga dari hal yang tidak diinginkan. Peraturan tersebut dapat dipahami oleh penumpang Trans Jateng hingga penumpang dengan sendirinya menyadari dan selalu mematuhi peraturan yang ada. Kepedulian pramujasa juga terlihat dari sikap-sikap yang ditujukan kepada penumpang. Pramujasa bersikap informatif dalam memberikan penjelasan terkait rute dan titik transit. Manajemen Trans Jateng telah mempersiapkan kru dengan memberikan pelatihan terkait pengetahuan operasional dan konsep dasar pelayanan. Sehingga diharapkan pramujasa dapat memahami teknis operasioanal dan akan membantu pengguna dalam memberikan informasi yang dibutuhkan. Pramujasa juga sangat komunikatif dengan penumpang dengan mengajak ngobrol disaat tidak sibuk. Hal-hal kecil seperti menanyakan tujuan perjalanan, keperluan perjalanan dan pertanyaan lain dengan sopan dapat menimbulkan kesan bahwa pramujasa peduli pada penumpang. Selain itu pramujasa selalu membantu penumpang saat naik dan turun dari bis, membantu dalam membawa masuk dan menata barang bawaan di dalam bis. Pramujasa dapat menghantarkan nilai kepedulian dan kemauan dalam melayani dan membantu penumpang sehingga pengguna dapat merasakan pelayanan pramujasa dengan baik.

\section{Analisis Kesenjangan Kualitas Jasa}

Pengguna Trans Jateng membentuk ekspektasi jasa dengan merasakan dan melihat dari pengalaman pribadinya menggunakan pelayanan jasa Trans Jateng. Pengguna akan membandingkan antara jasa yang telah didapatkan dengan yang diharapkan. Menurut persepsi pengguna, pelayanan yang diberikan Trans Jateng saat ini sudah sesuai dengan ekspektasi yang diharapkan oleh pengguna. Begitu juga dengan fasilitas yang didapat sangat setimpal dengan harga yang sangat murah sehingga pengguna merasa puas dengan layanan transportasi massal Trans Jateng.

Pelayanan jasa yang dirasakan dan diharapkan pengguna sudah sesuai dengan gambaran pelayanan yang ingin disampaikan oleh manajemen Trans Jateng. Pelayanan yang dapat mengakomodir permintaan dan kebutuhanmasyarakat. Pelayanan transportasi yang menjamin kebutuhan dasar masyarakat yaitu transportasi yang murah, aman, tepat waktu, terjamin ketersediaannya, terjadwal, dan nyaman. Diharapkan 
dengan adanya pelayanan yang mendekati keinginan dasar masyarakat, maka akan membuat pengguna menjadi lebih puas dengan fasilitasi angkutan umum massal.

Pengguna berharap agar layanan Trans Jateng yang dinilai sejauh ini sudah cukup baik agar selalu dipertahankan. Berberapa memberikan masukan bahwa perlu adanya peningkatan terkait attitude kru, penambahan armada, suhu dalam bis dijaga agar tetap dingin, dan merubah teknis transaksi tiket agar tidak terlalu rumit jika di dalam bis. Namun pada penerapannya, walaupun pengguna mengatakan bahwa pelayanan kru sejauh ini sudah cukup baik, beberapa kru sebagai orang-orang garis depan dalam pelayanan kurang mampu menghantarkan nilai yang baik.

Pengguna menilai bahwa perlu ada peningkatan pada attitude kru, hal ini disebabkan masih ada beberapa kru pramujasa kurang peduli kepada pengguna dan beberapa kurang menerapkan $3 \mathrm{~S}$ (senyum, salam, sapa) dengan baik. Hal ini dapat mengurangi penilaian pengguna terhadap gambaran pelayanan yang prima pada kru Trans Jateng. Sikap dan kondisi kru sangat mempengaruhi penyampaian pelayanan kepada pengguna, jika kru sedang tidak dalam kondisi terbaiknya, maka kemungkinan pelayanan tidak dapat memenuhi standar kualitas pelayanan yang diharapkan oleh pengguna. Hal ini akan menimbulkan rasa kecewa dan pengguna akan merasakan pengalaman yang kurang menyenangkan dari sikap kru yang kurang positif. Selain itu kru tersebut belum dapat memenuhi harapan manajemen dalam memberikan pelayanan yang terbaik dalam berinteraksi dengan penumpang.

Selain itu pengguna mengatakan bahwa masih ada beberapa kru pengemudi yang terlalu cepat, ngerem mendadak, bahkan ngebut dalam mengemudi kendaraannya. Hal ini akan berpengaruh kepada penilaian pengguna terhadap keamanan penumpang selama perjalanan dengan menggunakan layanan jasa Trans Jateng. Manajemen pun berharap dengan memberikan pelatihan cara mengemudi dan berlalu lintas yang baik, pengemudi tidak ngebut dan ugal-ugalan. Sehingga kru tersebut belum dapat memenuhi harapan manajemen untuk menjalankan tugasnya dengan baik dan menghantarkan gambaran pelayanan yang aman kepada penumpang.

Jika dilihat dari realita diatas, dapat diidentifikasikan bahwa terdapat kesenjangan antara spesifikasi kualitas pelayanan dan pemberian/penyampaian pelayanan kepada pengguna (gap 3), khususnya pada dimensi bukti fisik dan jaminan. Faktor yang menyebabkan adanya gap pada pelayanan jasa Trans Jateng yaitu adanya ambiguitas pesan, dimana beberapa kru kurang memberikan pelayanan yang prima sehingga belum memenuhi harapan manajemen dalam melakukan tugas dengan baik untuk melayani pengguna jasa Trans Jateng. Beberapa kru belum dapat memenuhi standar kualitas yang telah ditetapkan, dalam memberikan pelayanan yang sesuai SOP. Seperti penerapan 3S (salam, senyum, sapa), sikap yang kurang care, dan masih adanya beberapa kru yang kurang aman dalam mengemudi. Dari hasil analisis diatas, Manajemen Trans Jateng harus meminimalisir kesenjangan antara jasa yang dirasakan dan jasa yang diharapkan, sehingga antara harapan konsumen mengenai jasa yang disampaikan dalam pelayanan kepada pengguna akan sesuai dengan persepsi konsumen atas jasa yang diterima. 


\section{PENUTUP}

\section{Kesimpulan}

Berdasarkan hasil analisis yang telah dilakukan terkait persepsi pengguna jasa Trans Jateng terhadap kualitas pelayanan angkutan aglomerasi perkotaan Trans Jateng dapat disimpulkan bahwa kualitas pelayanan pada Trans Jateng sudah baik. Persepsi pengguna terhadap pelayanan Trans Jateng sudah sesuai dengan ekspektasi yang diharapkan oleh pengguna. Kru dan manajemen Trans Jateng berhasil menghantarkan jasa yang nyaman, aman, murah, terjangkau, tepat waktu, dan terjamin ketersediaannya. Sehingga angkutan aglomerasi perkotaan Trans Jateng menjadi angkutan massal yang dapat diandalkan bagi masyarakat khususnya pengguna antar Kabupaten Semarang dan Kota Semarang. Hasil identifikasi persepsi pengguna terkait lima dimensi kualitas jasa Trans Jateng adalah sebagai berikut :

1. Keandalan : pengguna mempersepsikan bahwa menggunakan Trans Jateng jauh lebih nyaman, hemat, cepat, murah, mudah dan pelayanannya bagus. Hal ini membuat nilai pelayanan yang dihantarkan oleh kru dan manajemen Trans Jateng telah diterima dan dipersepsikan dengan baik oleh pengguna

2. Bukti fisik : pengguna mempresepsikan bahwa pelayanan, kondisi bus, kenyamanan, jadwal kedatangan bus dan tarif sudah cukup bagus. Namun pengguna juga mengatakan bahwa ada beberapa kru yang kurang pedulidan kurang baik dalam menerapkan $3 \mathrm{~S}$, sehingga pelayanan menjadi kurang prima dan dapat berpengaruh dalam penghantaran nilai yang baik

kepada pelanggan.

3. Tanggapan : Pengguna menilai manajemen Trans Jateng cepat dalammenanggapi komplain serta mengeksekusi masukan dan keluhan yang ada. Namun perlu ada peningkatan dalam pelayanan dan penambahan informasi pada aplikasi Trans Jateng. Pengguna telah memanfaatkan kanal aduan untuk menyampaikan masukan dan keluhan mereka. Namun ada juga pengguna yang tidak tahu bagaimana atau kemana mereka menyampaikan

masukan dan keluhan tersebut.

4. Jaminan : pengguna menilai bahwa keamanan di dalam bis dan di halte selama ini aman. Hal ini didukung dengan adanya peraturan terkait pemisahan penumpang dan kru yang ikut menjaga barang bawaan penumpang. Supir Trans Jateng dinilai sudah menaati aturan lalu lintas yang ada, akan tetapi masih ada beberapa kru pengemudi yang ngebut/ugal-ugalan. Hal ini dapat memberikan penilaian negatif pada pelayanan Trans Jateng

5. Empati : pramujasa dinilai bersikap peduli kepada penumpang, terlebih kepada ibu hamil, lansia, dan anak kecil. Selain itu pramujasa juga sangat komunikatif, informatif, dan selalu membantu penumpang. Hal tersebut membuktikan bahwa pramujasa dapat menghantarkan nilai kepedulian dengan kemauan dalam melayani dan membantu penumpang sehingga pengguna dapat merasakan pelayanan pramujasa dengan baik. 
Pengguna berharap layanan Trans Jateng yang dinilai sejauh ini sudah cukup baik agar selalu dipertahankan. Namun pengguna juga menyampaikan beberapa hal yang perlu ditingkatkan pada pelayanan Trans Jateng. Hal yang perlu ditingkatkan yaitu pada kinerja beberapa kru yang kurang memberikan pelayanan secara prima kepada pengguna sehingga belum memenuhi harapan manajemen dalam melakukan tugas dengan baik untuk melayani pengguna jasa Trans Jateng. Hal tersebut membuktikan adanya ambiguitas pesan, yang merupakan salah satu faktor terjadinya suatu kesenjangan antara spesifikasi kualitas pelayanan dan pemberian/penyampaian pelayanan kepada pengguna (gap 3), khususnya pada dimensi bukti fisik dan jaminan. Untuk itu Manajemen Trans Jateng perlu meminimalisir kesenjangan antara jasa yang dirasakan dan jasa yang diharapkan guna meningkatkan kualitas pelayanan dan kepuasan pengguna Trans Jateng.

\section{Saran}

Berdasarkan hasil penelitian yang telah dilakukan pada Pelayanan Angkutan Aglomerasi Perkotaan Trans Jateng Koridor I Semarang (Tawang) - Bawen, maka penulis mengemukakan beberapa saran yang dapat digunakan manajemen Trans Jateng untuk meningkatkan pelayanan dan penciptaan nilai yang lebih baik kepada pengguna yaitu sebagai berikut :

1) Pengguna merasa bahwa penarikan tiket oleh pramujasa di dalam bis kurang praktis, sehingga sebaiknya manajemen Trans Jateng perlu merubah sistem penarikan tiket di dalam bis agar penarikan tiket lebih teratur dan lebih praktis. Terdapat dua alternatif saran yang dapat dilakukan yaitu :

$\checkmark$ Merubah SOP penarikan tiket di dalam bis, Pramujasa dapat menarik tiket sebelum penumpang masuk ke dalam bis (setelah menarik tiket Pramujasa tetap ikut dalam perjalanan).

$\checkmark$ Menggunakan mesin pembayaran di dekat pintu masuk berbasis kartu guna membiasakan pengguna agar beralih ke pembayaran secara non tunai yang juga bermanfaat guna mengurangi kebocoran pendapatan.

Walaupun pembayaran tiket dilakukan di awal, Namun Pramujasa tetap perlu ikut selama perjalanan di dalam bis untuk membantu dan memberikan layanan kepada penumpang selama perjalanan.

2) Aplikasi Trans Jateng sangat bermanfaat bagi pengguna jasa yang menggunakannya untuk memantau kedatangan bis, namun aplikasi tersebut kurang informatif sehingga terkadang pengguna merasa kecewa apabila bis yang datang tidak berhenti pada halte karena penuh dan melewati pengguna yang sedang menunggu bis. Maka dari itu Manajemen Trans Jateng perlu menambah informasi pada aplikasi Trans Jateng (Si Anteng) terkait :

$\checkmark$ Estimasi waktu kedatangan bis yang akurat beserta estimasi waktu kedatangan bis berikutnya agar pengguna dapat memperkirakan waktu tunggu dan menyesuaikan waktu mendapat bis secara tepat; 
$\checkmark$ Informasi jumlah penumpang di dalam bus agar penumpang dapat memastikan bahwa mereka dapat masuk ke dalam bis yang akan datang atau harus menunggu bis berikutnya karena bis yang akan datang penuh.

3) Pada hasil penelitian ditemukan adanya kesenjangan antara spesifikasi kualitas pelayanan dan pemberian/penyampaian pelayanan kepada pengguna. Maka dari itu saran untuk menghilangkan kesenjangan antara kondisi yang diharapkan dengan yang riil terjadi adalah sebagai berikut :

$\checkmark$ Manajemen Trans Jateng perlumerancang suatu program pelatihan guna meningkatkan kinerja Pramujasa dan Pramudi, yaitu :

- Merancang program pelatihan untuk Pramujasa menggunakan jenis pelatihan Behavioral Modelling (untuk meningkatkan dan mengembangkan kemampuan interpersonal dalam menjalani pekerjaan mereka di sektor pelayanan) dengan menanamkan kembali pelayanan yang berorientasi kuat kepada pengguna serta memotivasi kru agar selalu menjunjung pelayanan prima dan meningkatkan komitmen mereka dalam bertugas sepenuh hati.

- Merancang program pelatihan keselamatan mengemudi kepada Pramudi dengan melibatkan pihak ketiga atau instansi terkait yang dapat memberikan materi dan simulasi tentang keselamatan berlalu lintas dan tata cara berkendara yang baik guna menumbuhkan budaya keselamatan serta tertib berlalu lintas demi menjaga kualitas pelayanan dan meningkatkan jaminan keamanan untuk pengguna jasa Trans Jateng.

Salah satu cara guna menciptakan semangat kerja dan mendorong sikap positif agar selalu terjaga yaitu memberikan penghargaan yang lebih efektif kepada kru yang telah berkinerja dengan baik dengan memberikan insentif, award kru terbaik setiap 1 bulan atau tiap 3 bulan sekali dengan hadiah khusus seperti tiket liburan atau voucher belanja.

\section{DAFTAR PUSTAKA}

A, Parasuraman. 2001. The Behaviorial Consequenses of Service Quality, Jurnal of Marketing, Vol 60.

Atmojo, A. Rinto Dwi. 2012 "Persepsi Pengunjung Terhadap Kualitas Pelayanan

Pada Museum Mulawarman Tenggarong”. JURNAL EKSIS Vol.8 No.1, Mar 2012: $2001-2181$

Budiono, Fahrizal Lukman. 2013. "Persepsi dan Harapan Pengguna terhadap Kualitas Layanan Data pada Smartphone di Jakarta”. Buletin Pos dan Telekomunikasi Vol 11, No 2

Kotler, Philip and Gary Armstrong. 2012. Prinsip-prinsip Pemasaran. Edisi 13. Jilid 1. Jakarta: Erlangga. 
Kotler, Philip and Gary Armstrong. 2014. Prinsip-prinsip Manajemen. Edisi 14. Jilid 1. Jakarta: Erlangga.

Peraturan Menteri Nomor 10 Tahun 2012 Tentang Standar Pelayanan Minimal Angkutan Massal Berbasis Jalan

Peraturan Menteri Nomor 15 tahun 2019 tentang penyelenggaraan angkutan orang dengan kendaraan umum dalam trayek

Peraturan Menteri Nomor 27 Tahun 2015 Perubahan Atas Peraturan Menteri

Perhubungan Nomor 10 Tahun 2012 Tentang Standar Pelayanan Minimal Angkutan Massal Berbasis Jalan

Peraturan Pemerintah Republik Indonesia Nomor 37 Tahun 2011 Tentang Forum Lalu Lintas dan Angkutan Jalan

Peraturan Pemerintah Republik Indonesia Nomor 74 Tahun 2014 Tentang Angkutan Jalan

Puji Astuti, dkk. 2018. "Persepsi Masyarakat Terhadap Fasilitas Dan Pelayanan Angkutan Umum Trans Metro Pekanbaru”. Jurnal Saintis, Vol 18. No. 2, 2018 : 23 $-32$

Putra S Deevaa Andri, dkk. 2016. "Kualitas Pelayanan BRT Trans Semarang Koridor II Rute Terboyo Sisemut Analisis Survei Kepuasan Masyarakat (Studi Evaluasi)". Journal Of Public Policy And Management Review Volume 5 Nomor 3

Sangadji., Etta Mamang \& Sopiah. 2013. Perilaku Konsumen - Pendekatan Praktis disertai Himpunan Jurnal Penelitian. Yogyakarta: ANDI

Tjiptono, Fandy dan Greogrius Chandra. 2012. Pemasaran Strategik. Andi, Yogyakarta. Tunjungsari., Komang Ratih, dkk, 2019. "Pelayanan Transportasi Umum Bus Trans Sarbagita Bagi Masyarakat Dan Pariwisata Kota Denpasar”. Jurnal Sains Terapan Pariwisata Vol.4, No. 1,p. 1-11

Umar, Husein. 2005, Riset Pemasaran danPerilaku Konsumen. Edisi keempat. Jakarta: PT. Gramedia Pustaka Utama. 